\title{
Peroxynitrite can affect platelet responses by inhibiting energy production
}

\author{
Tomasz Rusak, Marian Tomasiak ${ }^{\bowtie}$ and Michal Ciborowski \\ Department of Physical Chemistry, Medical University of Bialystok, Biatystok, Poland; \\ 凶e-mail: mtomask@amb.edu.pl
}

Received: 08 September, 2006; revised: 27 September, 2006; accepted: 09 October, 2006 available on-line: 27 October, 2006

\begin{abstract}
Peroxynitrite $\left(\mathrm{ONOO}^{-}\right)$strongly inhibits agonist-induced platelet responses. However, the mechanisms involved are not completely defined. Using porcine platelets, we tested the hypothesis that $\mathrm{ONOO}^{-}$reduces platelet aggregation and dense granule secretion by inhibiting energy production. It was found that $\mathrm{ONOO}^{-}(25-300 \mu \mathrm{M})$ inhibited collagen-induced dense granule secretion $\left(\mathrm{IC}_{50}=55 \pm 7 \mu \mathrm{M}\right)$ more strongly than aggregation $\left(\mathrm{IC}_{50}=124 \pm 16 \mu \mathrm{M}\right)$. The antiaggregatory and antisecretory effects of $\mathrm{ONOO}^{-}$were only slightly $(5-10 \%)$ reduced by $1 \mathrm{H}-[1,2,4]$-oxadiazolo-[4,3$\alpha$ ]quinoxalin-1-one (ODQ), an inhibitor of soluble guanylate cyclase. In resting platelets $\mathrm{ONOO}^{-}$ $(50-300 \mu \mathrm{M})$ enhanced glycolysis rate and reduced oxygen consumption, in a dose dependent manner. The $\mathrm{ONOO}^{-}$effects on glycolysis rate and oxygen consumption were not abolished by ODQ. The extent of glycolysis stimulation exerted by $\mathrm{ONOO}^{-}$was similar to that produced by respiratory chain inhibitors (cyanide and antimycin A) or an uncoupler (2,4-dinitrophenol). Stimulation of platelets by collagen was associated with a rise in mitochondrial oxygen consumption, accelerated lactate production, and unchanged intracellular ATP content. In contrast to resting cells, in collagen-stimulated platelets, $\mathrm{ONOO}^{-}(200 \mu \mathrm{M})$ distinctly decreased the cellular ATP content. The glycolytic activity and oxygen consumption of resting platelets were not affected by 8-bromoguanosine $3^{\prime}, 5^{\prime}$-cyclic monophosphate. Blocking of the mitochondrial ATP production by antimycin A slightly reduced collagen-induced aggregation and strongly inhibited dense granule secretion. Treatment of platelets with $\mathrm{ONOO}^{-}(50-300 \mu \mathrm{M})$ resulted in decreased activities of NADH:ubiquinone oxidoreductase, succinate dehydrogenase and cytochrome oxidase. It is concluded that the inhibitory effect of $\mathrm{ONOO}^{-}$on platelet secretion and to a lesser extent on aggregation may be mediated, at least in part, by the reduction of mitochondrial energy production.
\end{abstract}

Keywords: aggregation, glycolysis, mitochondria, peroxynitrite, porcine platelets, secretion

\section{INTRODUCTION}

Peroxynitrite $\left(\mathrm{ONOO}^{-}\right.$, oxoperoxonitrate $\left.(-1)\right)$ is a potent oxidant and nitrating agent formed by the rapid reaction between superoxide $\left(\mathrm{O}_{2}^{--}\right)$and nitric oxide (NO) (Beckman \& Koppenol, 1996; Murphy et al., 1998). Formation of large quantities of $\mathrm{ONOO}^{-}$is expected to occur during ischemia-reperfusion injury, sepsis, neurodegenerative diseases and inflammatory processes where $\mathrm{NO}$ and $\mathrm{O}_{2}{ }^{--}$production is elevated (Radi et al., 2001). The main source of $\mathrm{ONOO}^{-}$in blood stream are activated circulating inflammatory cells, e.g. neutrophiles and monocytes (Ischiropoulos et al., 1992). Activated platelets may also release small amounts of $\mathrm{ONOO}^{-}$since they have been proposed to generate both $\mathrm{NO}$ and $\mathrm{O}_{2}{ }^{--}$ (Malinski et al., 1993; Marcus et al., 1997; Boulos et al., 2000). Appearing in the blood stream, $\mathrm{ONOO}^{-}$is therefore likely to interact with platelets. In vitro micromolar concentrations of $\mathrm{ONOO}^{-}$are able to affect some platelet responses (Moro et al., 1994; Boulos et al., 2000; Nowak \& Wachowicz, 2001). However, the results of those studies are conflicting. It has been reported that $\mathrm{ONOO}^{-}$may either strongly reduce platelet responses or behave as an inducer of their aggregation (Moro et al., 1994; Brown et al., 1998). The mechanisms underlying interactions of $\mathrm{ONOO}^{-}$ with platelets are not clear. It was hypothesized that 
$\mathrm{ONOO}^{-}$may affect platelets through the nitration of protein tyrosine residues (Brown et al., 1998; Boulos et al., 2000), but it soon appeared that nitrotyrosinecontaining proteins are found also in the cells activated by collagen, i.e. in the absence of exogenous peroxynitrite (Naseem et. al., 2000). It has also been proposed that in the presence of naturally occurring $\mathrm{SH}$-containing compounds (e.g. glutathione) $\mathrm{ONOO}^{-}$ can be converted to nitrosothiols, which may act as NO donors. Thus produced NO was suggested to inhibit platelet responses via the stimulation of soluble guanylate cyclase (Brown et al., 1998). It was also reported that $\mathrm{ONOO}^{-}$might affect platelets nonspecifically via peroxidation of membrane lipids (Nowak \& Wachowicz, 2001).

Studies performed on cells other then platelets have shown that $\mathrm{ONOO}^{-}$may strongly diminish mitochondrial respiration (Radi et al., 2002). Platelets possess mitochondria and oxidative energy production in resting (unstimulated) cells provides up to $50 \%$ of the total ATP formed (Holmsen, 1981). Metabolically, platelets are relatively active and have a total ATP turnover rate of about 3-8 times that of resting mammalian muscle (Akkerman 1978; Akkerman et al., 1978; Niu et al., 1996). Unstimulated platelets use the energy in the processes enabling them to be permanently in the responsive state. In activated platelets metabolic energy is required mainly for secretion and aggregation (Holmsen, 1981). Therefore the inhibition of platelet energy production may have critical implications for their responses (Holmsen et al., 1982; Verhoeven et al., 1984; Guppy et al., 1995). Consequently, the present study was performed to test the hypothesis that $\mathrm{ONOO}^{-}$may affect platelet responses through the inhibition of energy production.

\section{MATERIALS AND METHODS}

Chemicals. Antimycin A, 2,4-dinitrophenol (DNP), $\quad 1 H$-[1,2,4]-oxadiazolo-[4,3- $\alpha$ ]quinoxalin-1-one (ODQ), 8-bromoguanosine 3',5'-cyclic monophosphate (8-BrcGMP) were purchased from Sigma Chemical Co. (St. Louis, MO, USA). Collagen (fibrillar, from equine tendon) was from Hormon Chemie (Munich, Germany).

Synthesis of $\mathrm{ONOO}^{-}$. Peroxynitrite was synthesized by the reaction of acidified $\mathrm{NaNO}_{2}(1.2 \mathrm{M})$ with $\mathrm{H}_{2} \mathrm{O}_{2}(1.4 \mathrm{M})$ in a quenched flow reactor (Koppenol et al., 1996). The excess of $\mathrm{H}_{2} \mathrm{O}_{2}$ was removed by passing of the product over a column filled with granular manganese dioxide. Stock solutions containing at least $200 \mathrm{mM} \mathrm{ONOO}^{-}$were prepared and stored at $-70^{\circ} \mathrm{C}$. The concentration was determined prior to each experiment by measuring the absorbance at $302 \mathrm{~nm}\left(\varepsilon_{302}=1670 \mathrm{M}^{-1} \mathrm{~cm}^{-1}\right)$. Decomposed
$\mathrm{ONOO}^{-}$was obtained by allowing the compound to decay in $0.5 \mathrm{M}$ phosphate buffer $(\mathrm{pH} 7.4)$ at $25^{\circ} \mathrm{C}$ for $30 \mathrm{~min}$.

Preparation of platelet-rich plasma (PRP) and platelet-poor plasma (PPP). Blood was collected in the local slaughterhouse from adult pigs. The blood was withdrawn by direct carotid catheterization and collected into $3.8 \%(\mathrm{w} / \mathrm{v})$ sodium citrate, one volume per nine volumes of blood. PRP was obtained by centrifugation of the blood at $200 \times g$ for $20 \mathrm{~min}$ at room temperature. PPP was obtained by further centrifugation of PRP at $2700 \times g$ for $10 \mathrm{~min}$.

Preparation of platelet concentrate. Blood collected into ACD $(0.075 \mathrm{M}$ citric acid, $0.085 \mathrm{M}$ sodium citrate and $0.11 \mathrm{M}$ glucose) solution (one volume per six volumes of blood) was used to prepare platelet concentrate (Tomasiak et al., 2004).

Preparation of platelet homogenates. Platelet homogenate was prepared from fresh blood as described previously (Tomasiak et al., 2004).

Assay of platelet aggregation. Platelet aggregation was followed turbidimetrically by recording the light transmission through a stirred platelet suspension in the plastic cuvette of an aggregometer (Elvi, Logos, Milan, Italy) at $37^{\circ} \mathrm{C}$ (Born \& Cross, 1963). All experiments were performed at least in quadruplicate using six different platelet preparations.

Simultaneous measurement of platelet aggregation and ATP secretion. The platelet release reaction was monitored simultaneously with optical aggregation using lumiaggregometer (Chrono-log Corp., Havertown, PA, USA). All procedures were conducted as described previously (Tomasiak et al., 2004). The chemiluminescence signal was converted to nanomoles ATP per $10^{8}$ cells by comparison with an ATP standard curve.

Measurement of serotonin secretion. Secretion was determined by the release of $\left[{ }^{3} \mathrm{H}\right]$ serotonin using a procedure described previously (Tomasiak et al., 2004).

Measurement of glycolysis in intact platelets. Platelets $\left(2 \times 10^{9}\right.$ platelets $\left./ \mathrm{ml}\right)$ suspended in dialyzed plasma were incubated at $37^{\circ} \mathrm{C}$ in plastic vessels (50 ml conical Falcon tubes) with gentle stirring under the atmosphere of $95 \% \mathrm{O}_{2}+5 \% \mathrm{CO}_{2}$. Every $5 \mathrm{~min}$ the $\mathrm{pH}$ of the incubation mixture was checked and, if necessary, corrected by the addition of $0.2 \mathrm{M} \mathrm{NaOH}$ (total volume of $\mathrm{NaOH}$ added never exceeded $5 \%$ of the volume of platelet suspension). Incubation was started by the addition of glucose to the final concentration of $10 \mathrm{mM}$ and was carried out for $30 \mathrm{~min}$. It was stopped by the addition of 3 volumes of cold $6 \%(\mathrm{w} / \mathrm{v})$ perchloric acid. Lactate was measured in deproteinized and neutralized extract (Gutmann \& Wahlefeld, 1985). The formation of lactate was found to be linear during $30 \mathrm{~min}$ of incubation. 
Measurement of glycolysis in cell-free system. Platelets obtained from 21 of blood were suspended in $20 \mathrm{ml}$ of dialyzed plasma. The concentrate was cooled to $0^{\circ} \mathrm{C}$, supplemented with dithiothreitol (1.5 mM final concentration) and disrupted sonically. Immediately after sonication samples were used for the measurement of glycolytic activity (Tomasiak et al., 2004).

Measurement of the respiration rate. Respiration was measured polarographically at $37^{\circ} \mathrm{C}$ with a Clark-type oxygen electrode (Yellow Springs, USA, model YSI 4004) in a closed plastic vessel of $2 \mathrm{ml}$.

Measurement of intracellular ATP. After incubations platelet suspensions $(1 \mathrm{ml})$ were supplemented with $3 \mathrm{ml}$ of ice cold $6 \%$ (w/v) perchloric acid, sonicated and left at $0^{\circ} \mathrm{C}$ for $20 \mathrm{~min}$. The extracts were centrifuged to remove protein and neutralized with ice cold $6 \mathrm{M} \mathrm{KOH} / 0.5 \mathrm{M}$ morpholine sulphonic acid. ATP content was determined in neutralized cellular extracts by the luciferase-luciferin assay (Holmsen et al., 1972).

Assays of succinate dehydrogenase, NADH:ubiquinone oxidoreductase, cytochrome $c$ oxidase activities were performed as described previously (Tomasiak et al., 2004).

Data analysis. Data reported in this paper are the mean $( \pm$ S.D. $)$ of the number of determinations indicated (n). Statistical analysis was performed by the Student's $t$-test and elaboration of experimental data by the use of Slide Write plus (Advanced Graphics Software, Inc. Carlsbad, CA, USA.)

\section{RESULTS}

Figure 1 illustrates the results of experiments in which the effect of increasing concentrations of $\mathrm{ONOO}^{-}$on collagen-induced platelet aggregation and dense granule secretion was studied. Dense granule secretion was determined using two independent methods, i.e. by luminometry which measured the ATP (nonmetabolic pool of nucleotide normally stored in dense granules) released from dense granules, and an isotopic method which determined the release of $\left[{ }^{3} \mathrm{H}\right]$ serotonin (stored in dense granules) from the platelets preloaded with tritiated serotonin. As it is seen, a two-minute incubation of platelets with $\mathrm{ONOO}^{-}(25-300 \mu \mathrm{M})$ inhibited, in a dose dependent manner, the aggregation and dense granule secretion induced by a threshold concentration of collagen. The estimated $\mathrm{IC}_{50}$ values for aggregation, ATP release and serotonin secretion were $124 \pm 18,55 \pm 7$, and $58 \pm 8 \mu \mathrm{M}$, respectively. Total inhibition of aggregation and secretion was observed in the presence of $250-300 \mu \mathrm{M} \mathrm{ONOO}^{-}$.

Experiments shown in Table 1 were performed to compare the susceptibility of (collagen-

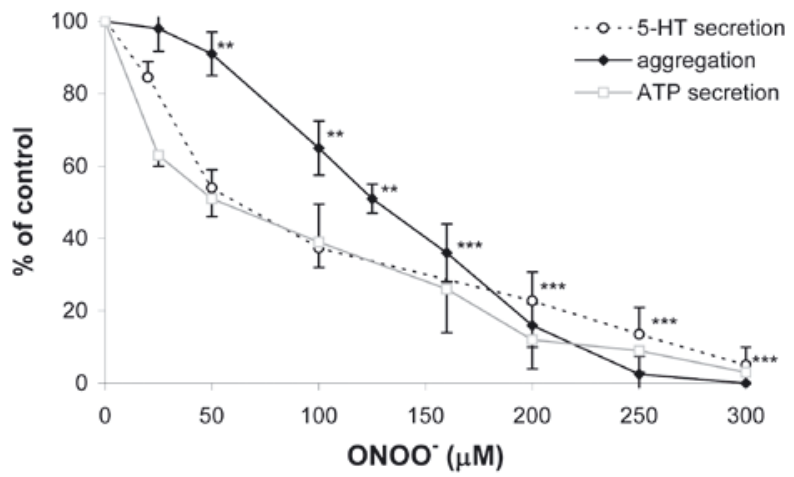

Figure 1. The effect of $\mathrm{ONOO}^{-}$treatment on platelet aggregation and dense granule secretion.

Aliquots $(0.5 \mathrm{ml})$ of PRP or washed platelets were incubated for $2 \mathrm{~min}$ at $37^{\circ} \mathrm{C}$ without (control) or with $\mathrm{ONOO}^{-}$ added to the final concentration as indicated. The extent of platelet aggregation $(\diamond)$, ATP secretion $(\square)$ and release of $\left[{ }^{3} \mathrm{H}\right]$ serotonin $(\mathrm{O})$ were measured $3 \mathrm{~min}$ after the addition of the threshold concentration of collagen $(15-20 \mu \mathrm{g} /$ $\mathrm{ml})$. Decomposed $\mathrm{ONOO}^{-}(300 \mu \mathrm{M})$ exerted no observable effect on collagen-induced aggregation and dense granule secretion. Aggregation, ATP secretion and $\left[{ }^{3} \mathrm{H}\right]$ serotonin release were monitored as under Methods. All experiments were performed at least in quadruplicate using five different platelet preparations. Means \pm S.D. are presented. The differences between the control and $\mathrm{ONOO}^{-}$-treated platelets are significant. ${ }^{* *} P<0.05 ;{ }^{* *} P<0.01$.

induced) platelet aggregation and secretion to the inhibition by $\mathrm{ONOO}^{-}$and a respiratory chain blocker, antimycin A. Platelet responses were measured in PRP samples using a lumiaggregometer. Aggregation and secretion of ATP from platelet dense granules were recorded simultaneously in the same platelet sample. Treatment of platelets with $100 \mu \mathrm{M}$ $\mathrm{ONOO}^{-}$resulted in a distinctly stronger inhibition of secretion (about 60\%) than aggregation (about 30\%). Similar results were obtained following the blocking of mitochondrial energy production by antimycin A. In this case pretreatment with $10 \mu \mathrm{M}$ antimycin A produced $25 \%$ and $75 \%$ inhibition of aggregation and secretion, respectively.

To estimate whether the inhibitory effect of $\mathrm{ONOO}^{-}$on platelet responses is mediated by NOstimulated guanylate cyclase (sGC) we studied the effect of ODQ, an inhibitor of sGC, on the antiaggregatory and antisecretory action of $\mathrm{ONOO}^{-}$in collagen-stimulated platelets. As is seen in Table 1 (panel B) concentrations of ODQ nearly completely reducing the antiaggregatory effect of sodium nitroprusside (NO donor) only slightly abolished the $\mathrm{ONOO}^{-}$effect on secretion (about $5 \%$ ) and aggregation (about 11\%).

The results presented in Table 2 show that the rate of glycolysis in intact platelets was increased by $\mathrm{ONOO}^{-}(25$ to $300 \mu \mathrm{M})$, respiratory chain blockers (cyanide, antimycin A), an uncoupler (2,4dinitrophenol), and following activation of platelets by collagen. Decomposed $\mathrm{ONOO}^{-}(300 \mu \mathrm{M})$ did not 
Table 1. The effect of $\mathrm{ONOO}^{-}$, sodium nitroprusside, and antimycin $\mathrm{A}$ on collagen-induced platelet aggregation and secretion

\begin{tabular}{llll}
\hline Experiment & Additions & Aggregation extent (\% of control) & Secretion (\% of control) \\
\hline \multirow{4}{*}{ A } & ONOO $^{-}(50 \mu \mathrm{M})$ & $92.6 \pm 6.8^{*}$ & $51.4 \pm 6.3^{* * *}$ \\
& ONOO $^{-}(100 \mu \mathrm{M})$ & $66.9 \pm 8.5^{* * *}$ & $38.4 \pm 6.7^{* * *}$ \\
& ONOO $^{-}(150 \mu \mathrm{M})$ & $39.6 \pm 9.2^{* * *}$ & $21.1 \pm 6.4^{* * *}$ \\
& Antimycin $(5 \mu \mathrm{g} / \mathrm{ml})$ & $92.2 \pm 7.6^{*}$ & $52.6 \pm 6.1^{* * *}$ \\
& Antimycin $(10 \mu \mathrm{g} / \mathrm{ml})$ & $89.6 \pm 8.1^{* *}$ & $39.7 \pm 7.1^{* * *}$ \\
& Antimycin $(20 \mu \mathrm{g} / \mathrm{ml})$ & $74.8 \pm 7.1^{* * *}$ & $24.9 \pm 5.2^{* * *}$ \\
\hline \multirow{4}{*}{ B } & ONOO- $(150 \mu \mathrm{M})$ & $41.6 \pm 9.4^{* * *}$ & $23.6 \pm 4.6^{* * *}$ \\
& ONOO $(150 \mu \mathrm{M})+\mathrm{ODQ}(20 \mu \mathrm{M})$ & $52.8 \pm 7.5^{* * *}$ & $28.7 \pm 4.8^{* * *}$ \\
& SNP $(25 \mu \mathrm{M})$ & $44.4 \pm 8.6^{* * *}$ & n.d. \\
& SNP $(25 \mu \mathrm{M})+$ ODQ $(10 \mu \mathrm{M})$ & $95.6 \pm 4.4$ & n.d. \\
\hline
\end{tabular}

PRP $(0.5 \mathrm{ml})$ was incubated at $37^{\circ} \mathrm{C}$ for $2 \mathrm{~min}$, without (control) or with tested substances added to the final concentrations as indicated. Aggregation and secretion were initiated by the addition of a supra-threshold concentration of collagen $(20 \mu \mathrm{g} / \mathrm{ml})$. Optical aggregation and dense granule secretion were monitored simultaneously as in Methods. The data represent mean values \pm S.D. of five experiments, each performed on separate platelet preparation $(\mathrm{n}=15) .{ }^{*} P<0.05,{ }^{* *} P<0.01,{ }^{* * *} P<0.005$.

affect glycolysis in intact platelets. The stimulatory effect of $\mathrm{ONOO}^{-}$on glycolysis was similar to that observed after the blocking of the respiratory chain by antimycin A or cyanide and to that produced by aggregating concentrations of collagen and was not abolished after the blocking of guanylate cyclase by ODQ. The rate of glycolysis in intact platelets was not affected following the treatment of the cells with 8-bromoguanosine 3',5'-cyclic monophosphate, a lipid-soluble analog of cGMP (Corbin et al., 1986) and

Table 2. Glycolytic activity of intact platelets in the presence of $\mathrm{ONOO}^{-}$, collagen, uncoupler of oxidative phosphorylation, respiratory chain blockers, and 8-BrcGMP

\begin{tabular}{|c|c|}
\hline Addition & $\begin{array}{l}\text { Lactate production } \\
\left(\mu \text { moles/min per } 10^{11} \text { cells) }\right.\end{array}$ \\
\hline None (control) & $3.1 \pm 0.2$ \\
\hline $25 \mu \mathrm{M} \mathrm{ONOO}^{-}$ & $3.5 \pm 0.3$ \\
\hline $50 \mu \mathrm{M} \mathrm{ONOO}-$ & $3.7 \pm 0.4$ * \\
\hline $100 \mu \mathrm{M} \mathrm{ONOO}^{-}$ & $4.1 \pm 0.5^{* *}$ \\
\hline $200 \mu \mathrm{M} \mathrm{ONOO}^{-}$ & $4.3 \pm 0.4^{* *}$ \\
\hline $300 \mu \mathrm{M} \mathrm{ONOO}{ }^{-}$ & $4.8 \pm 0.5^{* * *}$ \\
\hline Decomposed $\mathrm{ONOO}^{-}(300 \mu \mathrm{M})$ & $3.2 \pm 0.3$ \\
\hline ODQ $(20 \mu \mathrm{M})$ & $3.2 \pm 0.3$ \\
\hline $\begin{array}{l}\text { ODQ }(20 \mu \mathrm{M})+ \\
50 \mu \mathrm{M} \mathrm{ONOO}^{-}\end{array}$ & $3.6 \pm 0.5^{*}$ \\
\hline $\begin{array}{l}\text { ODQ }(20 \mu \mathrm{M})+ \\
200 \mu \mathrm{M} \mathrm{ONOO}^{-}\end{array}$ & $4.4 \pm 0.4^{* *}$ \\
\hline Collagen $(20 \mu \mathrm{g} / \mathrm{ml})$ & $5.2 \pm 0.3^{* * *}$ \\
\hline Antimycin A $(10 \mu \mathrm{g} / \mathrm{ml})$ & $4.8 \pm 0.2^{* * *}$ \\
\hline Cyanide (1 mM) & $5.1 \pm 0.3^{* * *}$ \\
\hline 2,4-Dinitrophenol (1 mM) & $5.5 \pm 0.3^{* * *}$ \\
\hline 8-BrcGMP (1 mM) & $3.0 \pm 0.3$ \\
\hline
\end{tabular}

Platelets $\left(2 \times 10^{9}\right.$ cells $\left./ \mathrm{ml}\right)$ suspended in dialyzed plasma were incubated at $37^{\circ} \mathrm{C}$ for $30 \mathrm{~min}$ without (control) and with various substances added to the final concentrations as indicated. Further details in Materials and Methods. The numbers are means \pm S.D. $(n=6)$ of one representative (out of six) experiment performed on single platelet preparation. Lactate production in the control varied from 2.7 to $3.8 \mu$ moles $\times \mathrm{min}^{-1} \times 10^{-11}$ cells. ${ }^{*} P<0.05,{ }^{* *} P<0.01$, ***P $<0.001$ a specific stimulator of protein kinase G (Lincoln \& Corbin, 1983)

To establish how $\mathrm{ONOO}^{-}$affects glycolysis in a cell-free system, i.e. in a system containing all the glycolytic enzymes and depleted of intact mitochondria, we measured the effect of $\mathrm{ONOO}^{-}$on lactate production in platelet homogenate. Platelet homogenate was used instead of a high-speed supernatant fraction (cytosol) since, as established by Akkerman (1978), 97\% of the total hexokinase activity in platelets is membrane bound (mitochondria). Respiratory chain blockers (cyanide, antimycin A), uncouplers (2,4-dinitrophenol) and $\mathrm{ONOO}^{-}(50-300 \mu \mathrm{M})$ did not affect the glycolysis rate measured in the cell-free system (not shown).

Table 3 shows that respiratory chain blockers (cyanide and antimycin A) and $\mathrm{ONOO}^{-}(50-300 \mu \mathrm{M})$ inhibited the oxygen consumption by unstimulated platelets. The effect exerted by $\mathrm{ONOO}^{-}$was dosedependent. The degree of this inhibition was similar to that observed in the presence of cyanide or antimycin A. In comparison to resting cells, collagenstimulated platelets demonstrated two times faster oxygen consumption. Decomposed $\mathrm{ONOO}^{-}$(300 $\mu \mathrm{M}$ ) did not affect the oxygen consumption by intact platelets. The inhibitory effect of $\mathrm{ONOO}^{-}$on respiration was not abolished following the blocking of guanylate cyclase by ODQ. In resting platelets a rise in the intracellular cGMP concentration evoked by a lipid-soluble analog (8-BrcGMP) did not modulate changes in oxygen consumption.

Table 4 illustrates the results of experiments which were performed to estimate whether in platelets $\mathrm{ONOO}^{-}$affects intracellular ATP content. As is seen, $\mathrm{ONOO}^{-}(100-300 \mu \mathrm{M})$ failed to affect distinctly the intracellular ATP content in resting cells and in platelets activated by collagen. By contrast, in collagen-stimulated platelets pretreated with $200 \mu \mathrm{M}$ $\mathrm{ONOO}^{-}$, a significant (about 30\%) reduction of intracellular ATP content was observed. Decomposed 
Table 3. Platelet oxygen consumption in the presence of $\mathrm{ONOO}^{-}$, respiratory chain inhibitors, 8-BrcGMP, and collagen

\begin{tabular}{|c|c|}
\hline Addition & $\begin{array}{l}\text { Oxygen consumption } \\
\text { (nmol } \mathrm{O}_{2} / \mathrm{min} \\
\text { per } 10^{11} \text { cells) }\end{array}$ \\
\hline None & $410 \pm 50$ \\
\hline Collagen $(20 \mu \mathrm{g} / \mathrm{ml})$ & $800 \pm 70^{* * *}$ \\
\hline Cyanide (1 mM) & $48 \pm 12^{* * *}$ \\
\hline Antimycin A $(10 \mu \mathrm{g} / \mathrm{ml})$ & $70 \pm 15^{* * *}$ \\
\hline 8-BrcGMP (1 mM) & $400 \pm 50$ \\
\hline $50 \mu \mathrm{M} \mathrm{ONOO}-$ & $280 \pm 50^{* *}$ \\
\hline $100 \mu \mathrm{M} \mathrm{ONOO}^{-}$ & $130 \pm 40^{* * *}$ \\
\hline $200 \mu \mathrm{M} \mathrm{ONOO}{ }^{-}$ & $80 \pm 30^{* * *}$ \\
\hline $300 \mu \mathrm{M} \mathrm{ONOO}^{-}$ & $50 \pm 30^{* * *}$ \\
\hline Decomposed $\mathrm{ONOO}^{-}(300 \mu \mathrm{M})$ & $390 \pm 50$ \\
\hline ODQ $(20 \mu \mathrm{M})+50 \mu \mathrm{M} \mathrm{ONOO}^{-}$ & $260 \pm 50 * *$ \\
\hline ODQ $(20 \mu \mathrm{M})+200 \mu \mathrm{M} \mathrm{ONOO}^{-}$ & $90 \pm 40^{* *}$ \\
\hline
\end{tabular}

Oxygen consumption was measured polarographically with a Clark oxygen electrode, in a closed plastic vessel of $2 \mathrm{ml}$ at $37^{\circ} \mathrm{C}$. Aliquots $(1 \mathrm{ml})$ of platelet concentrate and $1 \mathrm{ml}$ of dialyzed plasma were added to the vessel to give the final concentration of 2 $\times 10^{9} \mathrm{cells} / \mathrm{ml}$. Measurements were started after $2 \mathrm{~min}$ preincubation and were carried out for $10 \mathrm{~min}$. Additions to the measuring system were done $3 \mathrm{~min}$ after starting the recording of oxygen consumption. No exogenous glucose was added. The results of one representative experiment (out of five) are presented. Oxygen consumption in the control varied from 320 to $440 \mathrm{nmol} \times \mathrm{min}^{-1} \times$ $10^{-11}$ cells. ${ }^{* *} P<0.05,{ }^{* * *} P<0.001$.

$\mathrm{ONOO}^{-}$did not affect the intracellular ATP concentration in resting or collagen-stimulated cells.

Table 5 demonstrates the results of experiments in which the effect of $\mathrm{ONOO}^{-}$on the activity of NADH:ubiquinone oxidoreductase, succinate dehydrogenase and cytochrome oxidase in platelet homogenate was studied. $\mathrm{ONOO}^{-}(50-300 \mu \mathrm{M})$ reduced, in a concentration-dependent fashion, the activity of all the enzymes studied. The sensitivity of the enzymes to $\mathrm{ONOO}^{-}$increased in the following order: cytochrome oxidase < succinate dehydrogenase < NADH:ubiquinone oxidoreductase. Thus, $200 \mu \mathrm{M} \mathrm{ONOO}-$ inhibited cytochrome oxidase, succinate dehydrogenase and NADH:ubiquinone oxidoreductase by about $12 \%, 20 \%$ and $33 \%$, respectively.

Table 5. The effect of $\mathrm{ONOO}^{-}$on the activity of NADH: ubiquinone oxidoreductase, succinate dehydrogenase and cytochrome oxidase

\begin{tabular}{llll}
\hline Addition & $\begin{array}{l}\text { NADH:ubiquinone oxidoreduc- } \\
\text { tase }\left(\mu \mathrm{moles} / \mathrm{min} \text { per } 10^{12} \text { cells }\right)\end{array}$ & $\begin{array}{l}\text { Succinate dehydrogenase } \\
\left(\mu \mathrm{moles} / \mathrm{min} \text { per } 10^{12} \text { cells }\right)\end{array}$ & $\begin{array}{l}\text { Cytochrome oxidase }(\mu \mathrm{mo}- \\
\left.\text { les/min per } 10^{12} \text { cells }\right)\end{array}$ \\
\hline None & $18.0 \pm 0.2$ & $0.98 \pm 0.05$ & $3.11 \pm 0.5$ \\
\hline $50 \mu \mathrm{M} \mathrm{ONOO}^{-}$ & $17.6 \pm 0.2$ & $0.94 \pm 0.05$ & $3.07 \pm 0.5$ \\
$100 \mu \mathrm{M} \mathrm{ONOO}^{-}$ & $13.5 \pm 0.5^{*}$ & $0.82 \pm 0.04^{* *}$ & $2.94 \pm 0.4$ \\
$200 \mu \mathrm{M} \mathrm{ONOO}^{-}$ & $11.1 \pm 1.2^{* * *}$ & $0.79 \pm 0.04^{* *}$ & $2.74 \pm 0.5^{* *}$ \\
$300 \mu \mathrm{M} \mathrm{ONOO}^{-}$ & $9.6 \pm 2.1^{* * *}$ & $0.67 \pm 0.07^{* *}$ & $2.21 \pm 0.5^{* * *}$ \\
Decomposed ONOO $^{-}(300 \mu \mathrm{M})$ & $17.9 \pm 0.3$ & $0.96 \pm 0.07$ & $3.07 \pm 0.4$ \\
\hline
\end{tabular}

Platelet homogenate was incubated for $20 \mathrm{~min}$ at $37^{\circ} \mathrm{C}$ with decomposed or native $\mathrm{ONOO}^{-}$added to the final concentration as indicated Then the activities of NADH:ubiquinone oxidoreductase, succinate dehydrogenase and cytochrome oxidase were measured as described in Materials and Methods. Results are expressed as micromoles of oxidized substrate (NADH, succinate, cytochrome c)/min per $10^{12}$ cells. Mean values \pm S.D. $(n=15)$ are reported. ${ }^{*} P<0.05,{ }^{* *} P<0.01,{ }^{* * *} P<0.001$.
Table 4. Effect of peroxynitrite on the total ATP content in resting and stimulated porcine blood platelets

\begin{tabular}{|c|c|}
\hline Addition & $\begin{array}{l}\text { ATP content } \\
\text { (nanomoles } \\
\text { per } 10^{8} \text { cells) }\end{array}$ \\
\hline None (control) & $2.87 \pm 0.49$ \\
\hline $100 \mu \mathrm{M} \mathrm{ONOO}{ }^{-}$ & $2.76 \pm 0.41$ \\
\hline $200 \mu \mathrm{M} \mathrm{ONOO}-$ & $2.42 \pm 0.56$ * \\
\hline $300 \mu \mathrm{M} \mathrm{ONOO}^{-}$ & $2.43 \pm 0.21 *$ \\
\hline Decomposed ONOO- $(300 \mu \mathrm{M})$ & $2.82 \pm 0.38$ \\
\hline Collagen $(20 \mu \mathrm{g} / \mathrm{ml})$ & $2.69 \pm 0.27$ \\
\hline Collagen $+200 \mu \mathrm{M} \mathrm{ONOO}^{-}$ & $1.91 \pm 0.36^{* * *}$ \\
\hline Collagen + decomposed $\mathrm{ONOO}^{-}(200 \mu \mathrm{M})$ & $2.73 \pm 0.31$ \\
\hline
\end{tabular}

Aliquots $(1 \mathrm{ml})$ of PRP were incubated for $5 \mathrm{~min}$ at $37^{\circ} \mathrm{C}$ without (control) or with $\mathrm{ONOO}^{-}$added to the final concentration as indicated. ATP was measured in deproteinized and neutralized extracts as described under Methods. The data represent mean values \pm S.D. of five experiments, each performed on separate platelet preparation $(\mathrm{n}=15) .{ }^{*} P<0.05,{ }^{* * *} P<0.005$.

\section{DISCUSSION}

The results presented here show that $\mathrm{ONOO}^{-}$ is a strong inhibitor of aggregation and secretion of porcine platelets. This is in agreement with previous reports (Moro et al., 1994; Nowak \& Wachowicz, 2001). It has been reported that activation of human platelets by high thrombin concentration is accompanied by the acceleration of lactate production and enhanced oxygen consumption (Akkerman \& Holmsen, 1981; Niu et al., 1996). Our results show that porcine platelets stimulated by collagen also produce more lactate and consume more oxygen indicating that both glycolytic and mitochondrial ATP production are necessary to support their responses. This implies that in platelets blocking of energy production is likely to diminish their responses.

The present results show, for the first time, that under aerobic conditions exogenously added $\mathrm{ONOO}^{-}$stimulates glycolysis in intact porcine platelets. The degree of this stimulation was similar to that observed after the blocking of mitochondrial energy production by an uncoupler (dinitrophenol) or 
by respiratory chain inhibitors (antimycin A or cyanide). At the same time $\mathrm{ONOO}^{-}$, dinitrophenol, antimycin A and cyanide had no effect on the rate of glycolysis in the platelet homogenate in which functional (coupled) mitochondria were apparently not present. Since in platelets glycolysis and mitochondrial respiration are tightly functionally connected (Guppy et al., 1995), this can be interpreted to mean that the stimulatory effect of $\mathrm{ONOO}^{-}$on glycolysis in intact platelets may be related to impairment of mitochondria. This interpretation is likely to be true since, as reported here, in porcine platelets $\mathrm{ONOO}^{-}$ is able to reduce mitochondrial oxygen consumption and to inhibit NADH:ubiquinone reductase, succinate dehydrogenase and cytochrome oxidase. Interestingly, the concentrations of $\mathrm{ONOO}^{-}$inhibiting mitochondrial respiration and respiratory chain complexes were similar to those stimulating glycolysis in intact platelets.

To sum up, $\mathrm{ONOO}^{-}$is able to reduce platelet mitochondrial energy production through the inhibition of respiratory chain complexes I, II and IV.

The current observations indicate that in porcine platelets respiratory chain enzymes differ in their sensitivity to $\mathrm{ONOO}^{-}$, which increases in the order: cytochrome oxidase < succinate dehydrogenase $<\mathrm{NADH}$ :ubiquinone reductase. This is consistent with the observation of Riobo et al. (2001) that in rat brain submitochondrial particles, complex I (NADH:ubiquinone reductase activity) is much more sensitive to peroxynitrite than complexes II and III.

Our results indicate that the $\mathrm{ONOO}^{-}$concentrations totally blocking mitochondrial respiration are not able to inhibit completely the activity of respiratory chain enzymes. This indicates that peroxynitrite may affect platelet mitochondria not only through the inhibition of respiratory chain complexes. Thus, other damaging effects of $\mathrm{ONOO}^{-}$on platelet mitochondria are also likely to take place.

Activation of porcine platelets by collagen was not associated with a drop in the total cellular ATP content, despite the fact that aggregation and secretion are known to consume large quantities of metabolic energy (Holmsen et al., 1982). This is because the accelerated oxidative and glycolytic ATP production have a capacity completely to meet the augmented (due to activation) energy demand. Also, no reduction in cellular ATP content was observed in resting platelets treated with $\mathrm{ONOO}^{-}$. In this case accelerated glycolysis apparently had the capacity to fully compensate the lack of mitochondrial energy production and to meet the relatively small cellular ATP demand expected in resting cells. This is consistent with the observation that in platelets incubated under hypoxic conditions cellular ATP level remained unchanged (Akahori et al., 1995). However, as is here reported, a distinct reduction of cellular ATP content was observed in activated (by collagen) platelets pretreated with $\mathrm{ONOO}^{-}$. In this case even accelerated glycolytic ATP production failed to fully compensate for the impaired (by $\mathrm{ONOO}^{-}$) mitochondrial ATP production and to meet the high metabolic energy demand of activated cells (Akkerman \& Holmsen, 1981).

Does the $\mathrm{ONOO}^{-}$-mediated blocking of mitochondrial energy production explain the inhibitory effect of this compound on in vitro platelet responses? As is shown here in porcine platelets, diminishing the mitochondrial energy production by antimycin A affects platelet secretion distinctly more strongly than aggregation. This is consistent with the suggestion that platelet responses have different metabolic energy requirements, which increase in the order: aggregation < dense and alpha granule secretion < lysosome secretion (Holmsen et al., 1982; Verhoeven et al., 1984; Morimoto \& Ogihara, 1996). A comparison of the concentrations of $\mathrm{ONOO}^{-}$affecting mitochondrial respiration with those reducing platelet aggregation and secretion indicates that $\mathrm{ONOO}^{-}$cannot reduce significantly platelet aggregation through the inhibition of oxidative energy production. By contrast, the concentrations of $\mathrm{ONOO}^{-}$inhibiting platelet secretion and mitochondrial respiration were similar. This and the observation that $\mathrm{ONOO}^{-}$inhibits dense granule secretion more strongly than aggregation implies that in porcine platelets $\mathrm{ONOO}^{-}$can affect the secretory process through the inhibition of mitochondrial energy production.

To sum up, the inhibitory effect of $\mathrm{ONOO}^{-}$on platelet secretion, and to a lesser extent on aggregation, may be related to the reduction of mitochondrial energy production.

$\mathrm{ONOO}^{-}$was also reported to react with intracellular components containing $\mathrm{SH}$-groups (e.g. glutathione) and to form nitrosothiols (Mayer et al., 1995). Nitric oxide released from spontaneously decomposed nitrosothiols was proposed to activate soluble guanylate cyclase (sGC) (Mayer et al., 1995) and to inhibit cytochrome oxidase (Brown, 2001). The rise in intracellular cGMP level thus produced (Danielewski et al., 2005) and reduction of mitochondrial energy production (Tomasiak et al., 2004) have been proposed to inhibit platelet activation. However, the results presented here indicate that soluble guanylate cyclase is not a predominant intracellular factor mediating the $\mathrm{ONOO}^{-}$action on platelets, although its involvement in the inhibition of aggregation (but not secretion) can not be completely excluded (Table 1). This is because blocking of the guanylate cyclase slightly affects $\mathrm{ONOO}^{-}$action on platelet aggregation and is practically without any effect on secretion. Guanylate cyclase cannot be in- 
volved in the inhibition of energy production either, since both glycolysis and mitochondrial respiration were not affected by an artificially elevated intracellular cGMP concentration. An involvement of NO in the $\mathrm{ONOO}^{-}$action on platelet cytochrome oxidase is also unlikely. A comparison of the ODQ (a guanylate cyclase inhibitor) effect on the antiaggregatory action of sodium nitroprusside (NO donor) and $\mathrm{ONOO}^{-}$indicates that in platelets treated with peroxynitrite, guanylate cyclase is not maximally activated apparently due to a lower NO concentration. Taking into account that NO inhibits purified sGC (from brain cells) at concentrations 50-100 lower then that required to inhibit cytochrome oxidase (Bellamy et al., 2002), a nitric oxide-dependent $\mathrm{ONOO}^{-}$action on cytochrome oxidase is also excluded.

In conclusion, our data show that: 1) in porcine platelets $\mathrm{ONOO}^{-}$is able to diminish mitochondrial respiration through the inhibition of respiratory chain complexes I, II and IV; 2) the inhibitory effect of $\mathrm{ONOO}^{-}$on platelet secretion (but not aggregation) can be attributed, at least in part, to the reduction of mitochondrial energy production.

\section{Acknowledgements}

This research was supported by grant $3 \mathrm{P} 05 \mathrm{~F}$ 00924 from the State Committee for Scientific Research $(\mathrm{KBN})$.

\section{REFERENCES}

Akahori M, Uedono Y, Yamagami K, Takeyama N, Kitazawa Y, Tanaka T (1995) Hypoxia alters the energy metabolism and aggregation of washed human platelets. Haematologia 26: 191-198.

Akkerman JW (1978) Regulation of carbohydrate metabolism in platelets. Thromb Haemost 39: 712-724.

Akkerman JW, Holmsen H (1981) Interrelationships among platelet responses: studies on the burst in proton liberation, lactate production, and oxygen uptake during platelet aggregation and $\mathrm{Ca}^{2+}$ secretion. Blood 57: 956-966.

Akkerman JW, Gorter G, Sixma JJ (1978) Regulation of glycolytic flux in human platelets: relation between energy production by glyco(geno)lysis and energy consumption. Biochim Biophys Acta 541: 241-250.

Beckman JS, Koppenol WH (1996) Nitric oxide, superoxide, and peroxynitrite: the good, the bad, and the ugly. Am J Physiol 271: C1424-1437.

Bellamy TC, Griffiths C, Garthwaite J (2002) Differential sensitivity of guanylyl cyclase and mitochondrial respiration to nitric oxide measured using clamped concentrations. J Biol Chem 277: 31801-31807.

Born GV, Cross MJ (1963) The aggregation of blood platelets. J Physiol 168: 178-195.

Boulos Ch, Jang H, Balazy M (2000) Diffusion of peroxynitrite into the human platelet inhibits cyclooxygenase via nitration of tyrosine residues. J Pharmacol Exp Ther 293: 222-229.
Brown GC (2001) Regulation of mitochondrial respiration by nitric oxide inhibition of cytochrome $c$ oxidase. Biochim Biophys Acta 1504: 46-57.

Brown A, Moro M, Masse J, Cramer EM, Radomski M, Darley-Usmar V (1998) Nitric oxide-dependent and independent effects on human platelets treated with peroxynitrite. Cardiovasc Res 40: 380-388.

Corbin JD, Ogreid D, Miller JP, Suva RH, Jastorff B, Doskeland SO (1986) Studies of cGMP analogs specificity and function of the two intrasubunit binding sites of cGMP-dependent protein kinase. J Biol Chem 261: 12081214.

Danielewski O, Schultess J, Smolenski A (2005) The NO/ cGMP pathway inhibits Rap 1 activation in human platelets via cGMP-dependent protein kinase I. Thromb Haemost 93: 319-325.

Guppy M, Abas L, Arthur PG, Whisson ME (1995) The Pasteur effect in human platelets: implications for storage and metabolic control. Br J Haematol 91: 752-757.

Gutmann I, Wahlefeld AW (1985) L-(+)-Lactate: determination with lactate dehydrogenase and NAD. In Methods of enzymatic analysis (Bergmeyer HU, ed) pp 1464-1468. $\mathrm{VCH}$ Velagsgesellschaft $\mathrm{mbH}$, Weiheim.

Holmsen H (1981) Biochemistry of the platelets: energy metabolism. In Hemostasis and thrombosis: basic principles and clinical practice (Colman RW, Hirsch J, Marder VJ, Salzman EW, eds) pp 431-443. JB Lippincott Comp, Philadeplphia.

Holmsen HE, Storm E, Day HJ (1972) Determination of ATP and ADP in blood platelets: a modification of the firefly luciferase assay for plasma. Anal Biochem 46: 481-502.

Holmsen H, Kaplan KL, Dangelmaier CA (1982) Differential energy requirements for platelet responses. Biochem J 208: 9-18.

Ischiropoulos H, Zhu L, Beckman JS (1992) Peroxynitrite formation from macrophage-derived nitric oxide. Arch Biochem Biophys 298: 446-451.

Koppenol WH, Kissner R, Beckman JS (1996) Syntheses of peroxynitrite: to go with the flow or on solid grounds? Methods Enzymol 269: 296-302.

Lincoln TM, Corbin JD (1983) Characterization and biological role of the CGMP-dependent protein kinase. Adv Cyclic Nucleotide Res 15: 140-192.

Malinski T, Radomski M, Taha Z, Moncada S (1993) Direct electrochemical measurement of nitric oxide released from human platelets. Biophys Biochem Res Commun 194: 960-965.

Marcus AJ, Silk ST, Safier LB, Ullmann HL (1997) Superoxide production and reducing activity in human platelets. J Clin Invest 59: 149-158.

Mayer B, Schrammel A, Klatt P, Koesling D, Schmidt K (1995) Peroxynitrite-induced accumulation of cyclic GMP in endothelial cells and stimulation of purified soluble guanylyl cyclase. Dependence on glutathione and possible role of S-nitrosation. I Biol Chem 270: 17355-17360.

Morimoto T, Ogihara S (1996) ATP is required in platelet serotonin exocytosis for protein phosphorylation and priming of secretory vesicles docked on the plasma membrane. J Cell Sci 109: 113-118.

Moro MA, Darley-Usmar VM, Goodwin DA, Read NG, Zamora-Pino R, Feelish M, Radomski MW, Moncada S (1994) Paradoxical fate and biological action of peroxynitrite on human platelets. Proc Natl Acad Sci USA 91: 6702-6706.

Murphy MP, Packer MA, Scarlett JL, Martin SW (1998) Peroxynitrite: a biologically significant oxidant. Gen Pharmac 31: 179-186. 
Naseem KM, Low SY, Sabetkar M, Bradley NJ, Khan J, Jacobs M, Bruckdorfer KR (2000) The nitration of platelet cytosolic proteins during agonist-induced activation of platelets. FEBS Lett 473: 119-122.

Niu X, Arthur P, Abas L, Whisson M, Guppy M (1996) Carbohydrate metabolism in human platelets in a low glucose medium under aerobic conditions. Biochim Biophys Acta 1291: 97-106.

Nowak P, Wachowicz B (2001) Studies on pig blood platelet responses to peroxynitrite action. Platelets 12: 376381.

Radi R, Peluffo G, Alvarez MN, Naviliat M, Cayota A (2001) Unraveling peroxynitrite formation in biological system. Free Radic Biol Med 30: 463-488.

Radi R, Cassina A, Hodara R, Quijano C, Castro L (2002) Peroxynitrite reactions and formation in mitochondria. Free Radic Biol Med 33: 1451-1464.
Riobo NA, Clementi E, Melani M, Boveris A, Cadenas E, Moncada S, Poderoso JJ (2001) Nitric oxide inhibits mitochondrial NADH:ubiquinone reductase activity through peroxynitrite formation. Biochem J 359: 139145.

Tomasiak M, Stelmach H, Rusak T, Wysocka J (2004) Nitric oxide and platelet energy metabolism. Acta Biochim Polon 51: 789-803.

Verhoeven AJ, Mommersteeg ME, Akkerman JW (1984) Metabolic energy is required in human platelets at any stage during optical aggregation and secretion. Biochim Biophys Acta 800: 242-250. 